\author{
Supporting Information:
}

\title{
Bifacial Perovskite Solar Cells via a Rapid
}

\section{Lamination Process}

Tianyang Li, Wiley A. Dunlap-Shohl, and David B. Mitzi*

Department of Mechanical Engineering and Materials Science and Department of Chemistry, Duke University, Durham, North Carolina 27708, United States

\section{Corresponding Author}

David B. Mitzi: david.mitzi@duke.edu

\section{Chemicals.}

$\mathrm{Pbl}_{2}$ (TCl, 99.99\%), methylammonium iodide (MAI) (Greatcell Solar), $\mathrm{SnO}_{2}$ nanoparticle dispersion (15 wt\%, Alfa Aesar), Spiro-OMeTAD $(99.7 \%$ sublimed grade, Borun Chemical), poly(3,4ethylenedioxythiophene):poly(styrene sulfonate) (PEDOT:PSS) (PH1000, 1.0-1.3 wt.\% in water, Ossila), Dsorbitol ( $\geqslant 99.5 \%$, Sigma Aldrich), 3,3'-(2,7-dibromo-9H-fluorene-9,9-diyl) bis(N,N-dimethylpropan-1amine) (FN-Br) (>98\%, Lumtec), (6,6)-phenyl C61 butyric acid methyl ester (PCBM) (>99.5\%, Lumtec), N,Ndimethylformamide (DMF) (anhydrous, Sigma Aldrich) and dimethyl sulfoxide (DMSO) (anhydrous, Sigma Aldrich) are used without further purification. 


\section{Experimental methods.}

Fabrication of Laminated Devices. Two substrates are prepared separately, one is composed of $\mathrm{ITO} / \mathrm{SnO}_{2} / \mathrm{PCBM} / \mathrm{MAPb}_{3} / \mathrm{Spiro}-\mathrm{OMeTAD}$ on a finger-patterned ITO substrate and the other is composed of ITO/PEDOT:PSS/D-sorbitol on a single-strip patterned ITO substrate. The substrate dimensions are shown below in Figure S1.

To prepare the bottom substrate, ITO substrates are firstly cleaned in deionized water, acetone and isopropanol by sonication and then UV-ozone cleaned for $15 \mathrm{~min}$. $\mathrm{SnO}_{2}$ nanoparticle dispersion is diluted with deionized water to $1 / 5$ concentration and spin coated onto the substrates at $3000 \mathrm{rpm}$ for $30 \mathrm{~s}$, followed by $150{ }^{\circ} \mathrm{C}$ annealing for $30 \mathrm{~min}$ and then another UV-ozone clean for $15 \mathrm{~min}$. The substrates are transferred into a nitrogen-filled glovebox and PCBM solution ( $5 \mathrm{mg} / \mathrm{mL}$ in chlorobenzene) is then spin coated on top of the $\mathrm{SnO}_{2}$ layer at $3000 \mathrm{rpm}$ for $30 \mathrm{~s}$, followed by $100{ }^{\circ} \mathrm{C}$ annealing for $10 \mathrm{~min} .1 .4 \mathrm{M}, 1.5 \mathrm{M}$ and 1.6M stoichiometric (from MAl and $\mathrm{Pbl}_{2}$ ) $\mathrm{MAPbl}_{3}$ precursor solutions in DMF/DMSO (9/1 vol.) are used to deposit films of different thickness. The precursor solution is spin coated at $4000 \mathrm{rpm}$ and, at $5 \mathrm{~s}$ after commencing the spinning, $0.25 \mathrm{~mL}$ of chlorobenzene is dripped onto the substrate. After $100{ }^{\circ} \mathrm{C}$ annealing for $10 \mathrm{~min}$ to form the $\mathrm{MAPbl}_{3}$ film, Spiro-OMeTAD solution $(20 \mathrm{mg} / \mathrm{mL})$ is then spin coated at $3000 \mathrm{rpm}$ for 30 s to finish the bottom substrate. The $\mathrm{SnO}_{2}$ and PCBM layers are too thin to directly observe using cross-section SEM images. The $\mathrm{MAPbl}_{3}$ layer thickness is estimated to be from $450-550 \mathrm{~nm}$, depending on the different precursor solution concentrations. The Spiro-OMeTAD layer thickness in this recipe is estimated to be $\sim 60 \mathrm{~nm}$ from cross-section SEM.

To prepare the top substrate, single-strip patterned ITO substrates are cleaned as described above and PEDOT:PSS solution (sonicated for $10 \mathrm{~min}$ before use) is thereafter deposited by spin coating in air at 4000 rpm for 30s. The as-deposited films were then transferred to a nitrogen-filled glovebox, where they were annealed at $140{ }^{\circ} \mathrm{C}$ for $10 \mathrm{~min} .1 .0 \mathrm{mg} / \mathrm{mL}$ D-sorbitol isopropanol solution is subsequently spin coated onto the PEDOT:PSS-coated substrates at $4000 \mathrm{rpm}$ for $25 \mathrm{~s}$ to finish the top substrate. The PEDOT:PSS 
layer is estimated to be $\sim 70 \mathrm{~nm}$ in thickness from cross-section SEM, but the D-sorbitol layer is too thin to distinguish in the SEM.

The two substrates are then transferred outside of the glovebox, and placed face to face before putting into the hot press. Lamination is completed on a custom-made hot press, with both bottom and top hot plate preheated to $100{ }^{\circ} \mathrm{C}$, followed by pressing for $45 \mathrm{~s}$ with approximately 2000 psi pressure applied on the substrates. After lamination, the hot press is cooled by flowing cold water through the hot press surfaces while gently reducing pressure, and the finished device is thereafter removed from the press. More detailed description of the custom-made hot press and assembly procedure can be found in our previous report. $^{1}$

Device and Film Characterization. Solar cells were characterized after fabrication by J-V and EQE measurements. Device J-V curves were collected using an Oriel solar simulator and Keithley 2401 sourcemeter under 1 sun AM1.5G illumination, calibrated using a reference Si solar cell from Newport Co. and maintained at 1 sun during measurement using a reference photodiode. The laminated devices were measured unmasked, and their active area is determined afterward by referencing the measured device short-circuit current $\mathrm{I}_{\mathrm{sc}}$ against the integrated $\mathrm{J}_{\mathrm{sc}}$ measured from EQE. Each $(\mathrm{J}, \mathrm{V})$ point was sampled after a 1s delay immediately following application of the bias. Stabilized photocurrent/efficiency measurements were collected using the same apparatus. After biasing at a selected voltage, current was recorded at a 1 $\mathrm{Hz}$ sampling rate. External quantum efficiency measurements were taken in AC mode with an Enlitech QER instrument, using excitation from a monochromated Xe lamp optically chopped at $165 \mathrm{~Hz}$.

Enhancement of performance with albedo light is tested by adding a background tilted $45^{\circ}$ with respect to the device and at $\sim 10 \mathrm{~cm}$ below the device (i.e., replacing an untilted black background placed immediately behind the device, which is considered "without background"). The efficiency measured with background is then compared with the one without background. Background materials used are $10 \mathrm{~cm}$ by 
$10 \mathrm{~cm}$ of plywood, cement block, sea sand in a large petri dish and white paper. Measurements are taken using a Sylvania 74052 LED lamp as the light source. The illumination position of 1 sun intensity (where the devices are placed) is determined by calibration using a reference cell.

Stability testing is carried out in a humidity chamber where the relative humidity is set to $50 \%$. The device is kept under continuous illumination under 1 sun intensity using a Sylvania 74052 LED lamp (calibrated by a reference cell to determine the illumination position of 1 sun intensity) for 100 hours. Devices in ambient air and light condition are kept in a room with relative humidity ranging from $25-45 \%$ and under fluorescent lighting. Devices are stored at room temperature and under open circuit condition. J-V measurements are taken at 2, 4, 8, 12, 24, 36, 48, 72 and 96 hour intervals on 8 devices each for the laminated and conventional devices.

X-ray diffraction (XRD) patterns of thin films were collected using a Panalytical Empyrean powder X-ray diffractometer with a $\mathrm{Cu} \mathrm{K \alpha}$ source and $45 \mathrm{kV} / 40 \mathrm{~mA}$ X-ray tube voltage/current. Scanning electron microscope (SEM) images and videos were taken on a FEI Apreo SEM using beam voltage/current of 2 $\mathrm{kV} / 25 \mathrm{pA}$. 


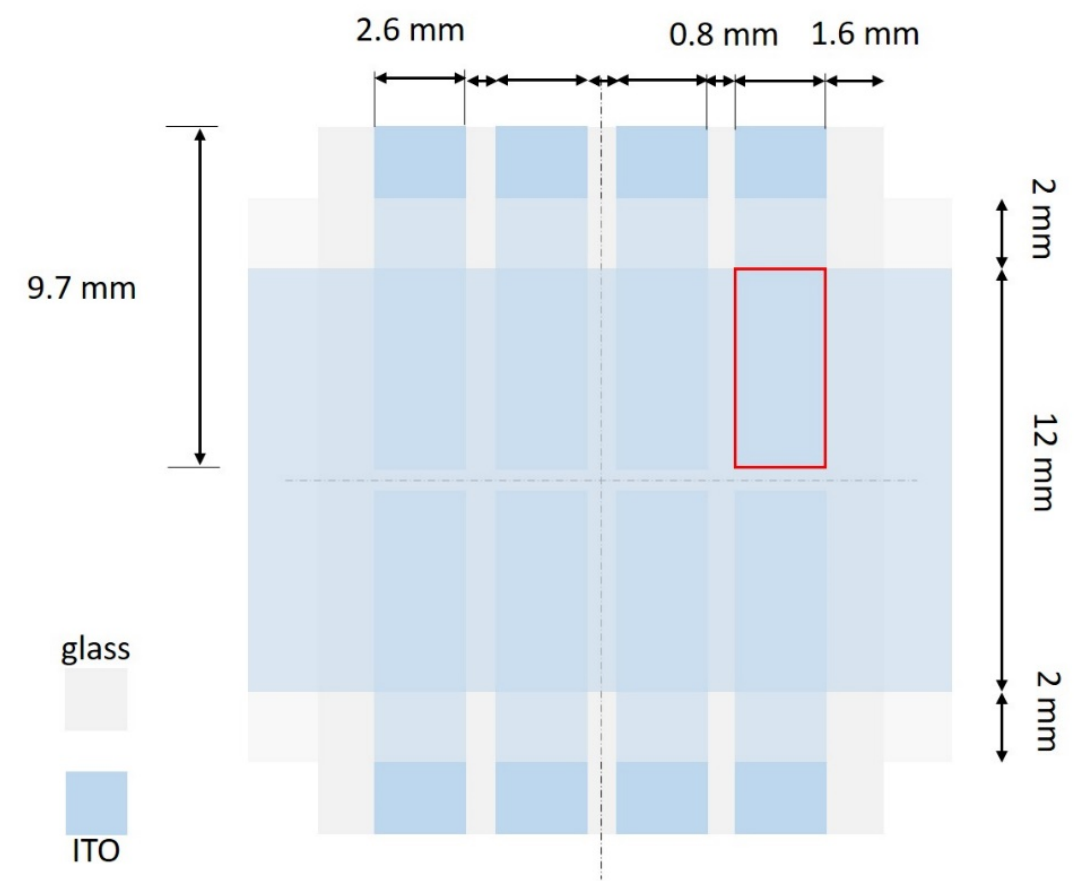

Figure S1. Schematic of substrate/superstrate alignment in laminated devices used in this work.

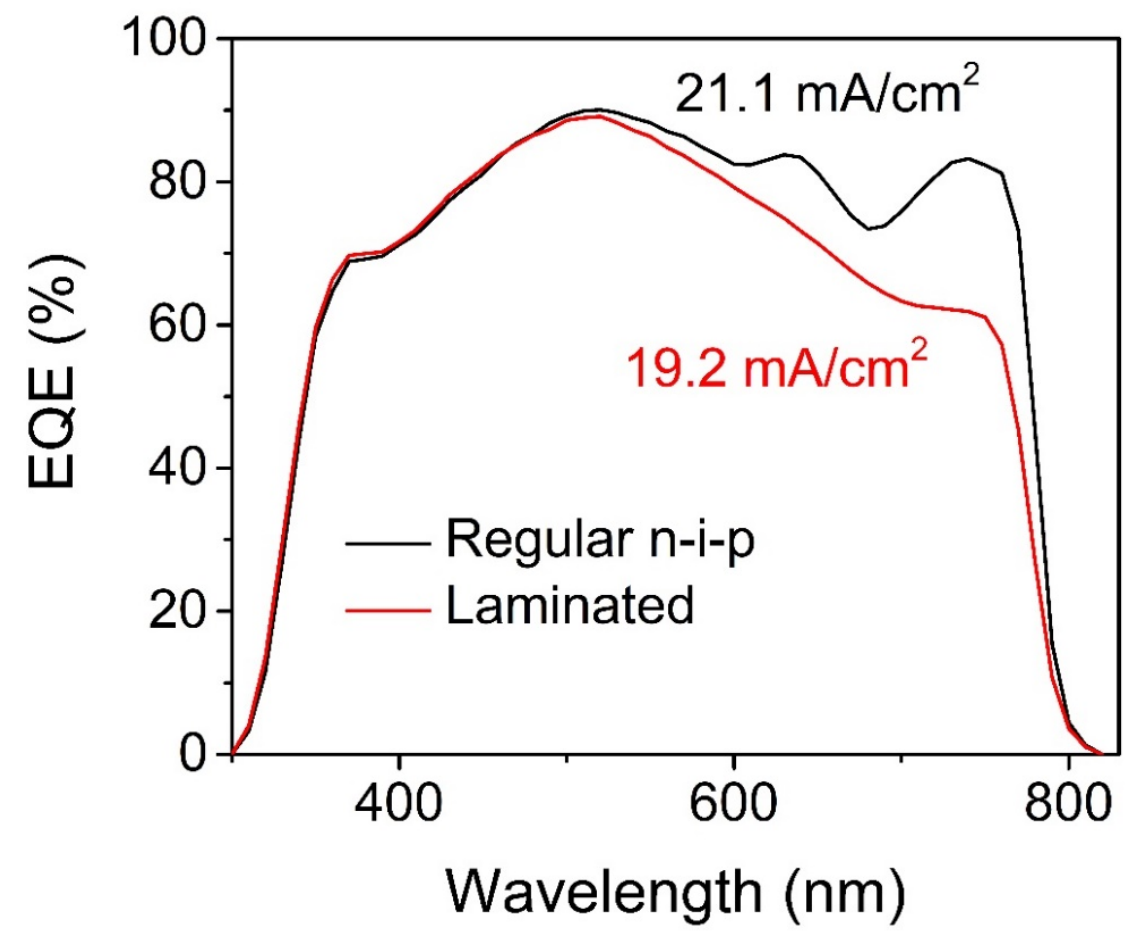

Figure S2. Comparison of EQE scans of a first-generation laminated device ${ }^{1}$ and a conventional (sequentially prepared) $\mathrm{SnO}_{2}$ based $n-i-p$ device. 


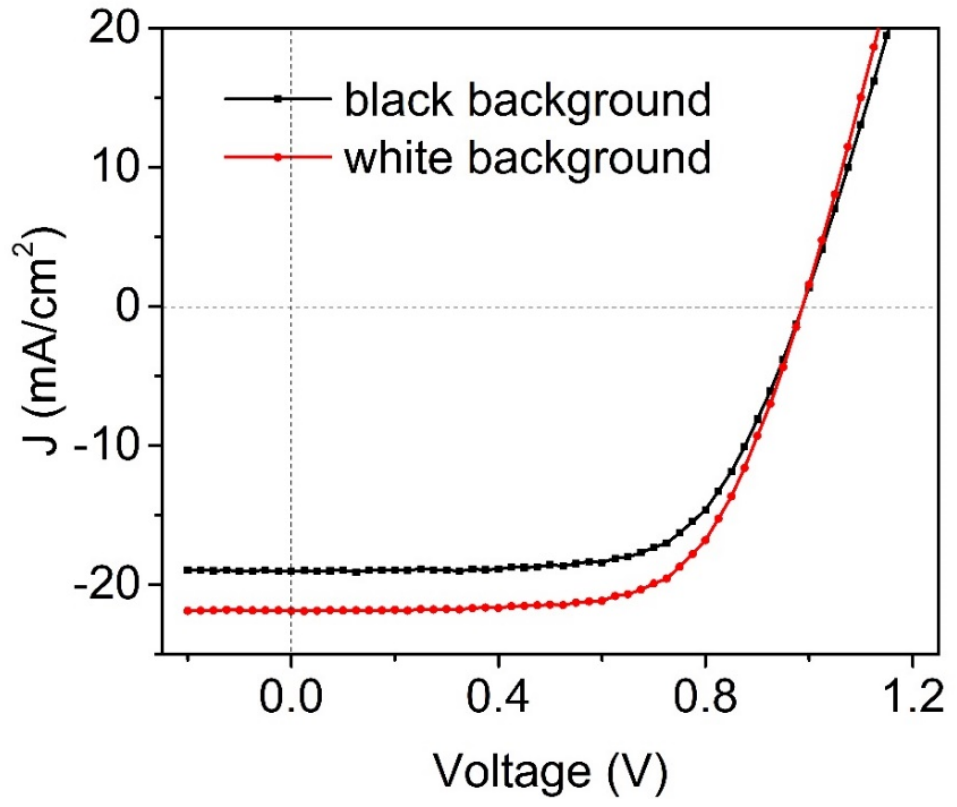

Figure S3. Comparison of J-V scans of the same laminated device (from Fig. S2) against a black and white background. The white background serves as a reflector, similar to the gold electrode of a conventional device.

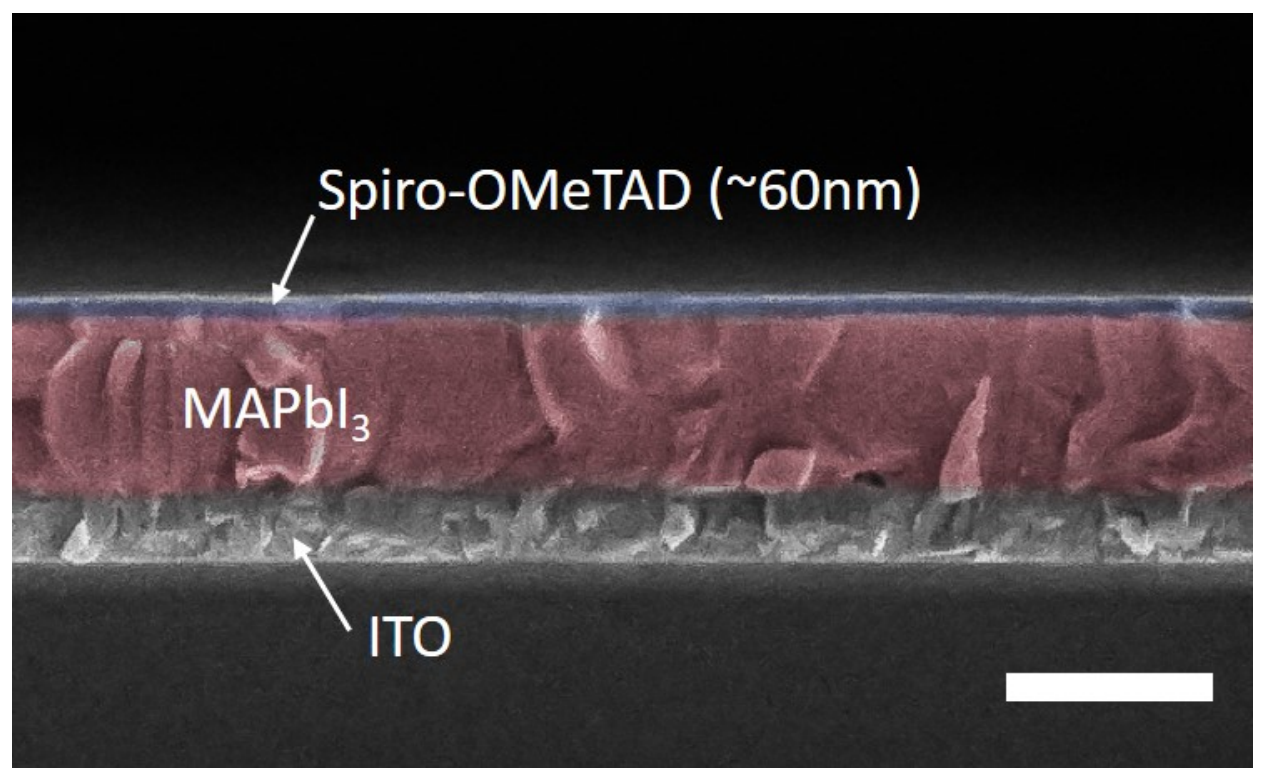

Figure S4. False-color cross-section SEM images of a half stack substrate of the laminated device, showing the thickness of the absorber and HTL layers, scale bar: $500 \mathrm{~nm}$. 
a

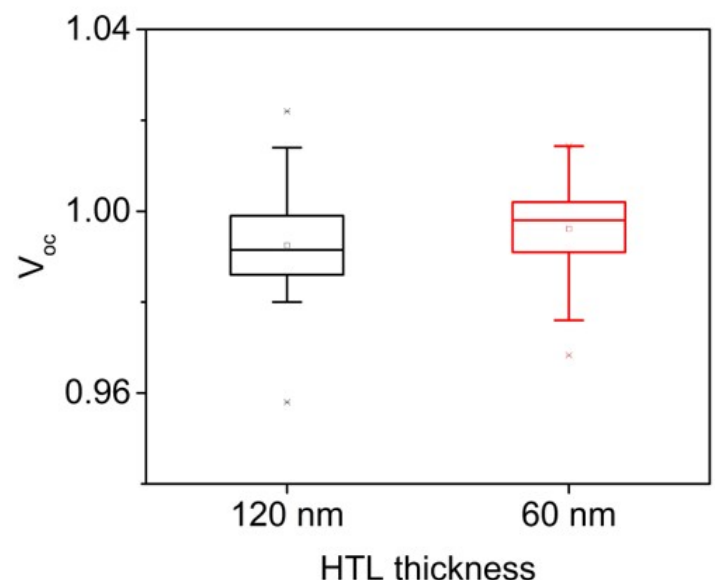

b

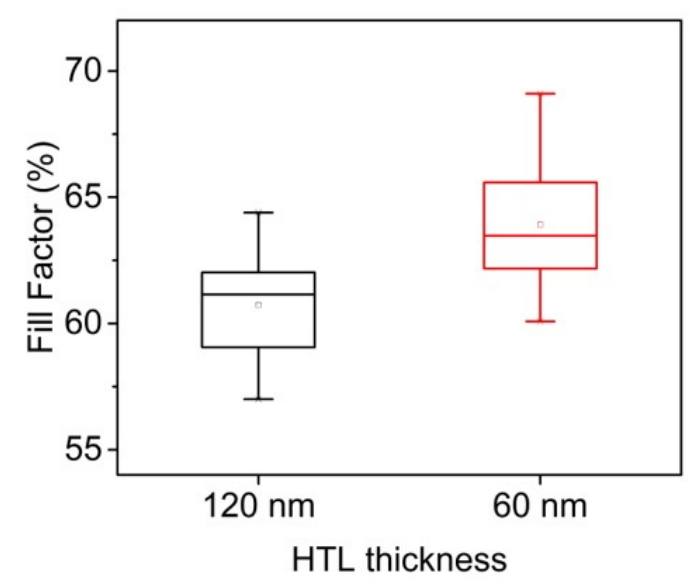

Figure S5. Open circuit voltage (a) and fill factor (b) statistics of laminated devices with different SpiroOMeTAD thickness (statistics obtained over 30 devices).

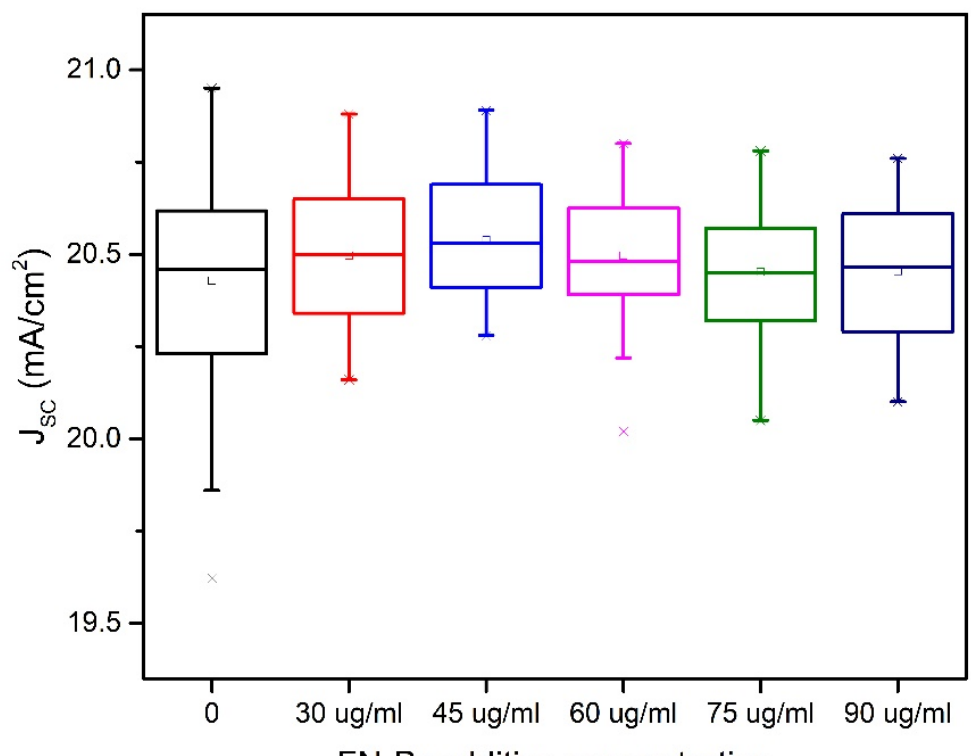

$\mathrm{FN}-\mathrm{Br}$ additive concentration

Figure S6. Short circuit current statistics of laminated devices using various concentration of additive FN$\mathrm{Br}$ in the Spiro-OMeTAD layer. 

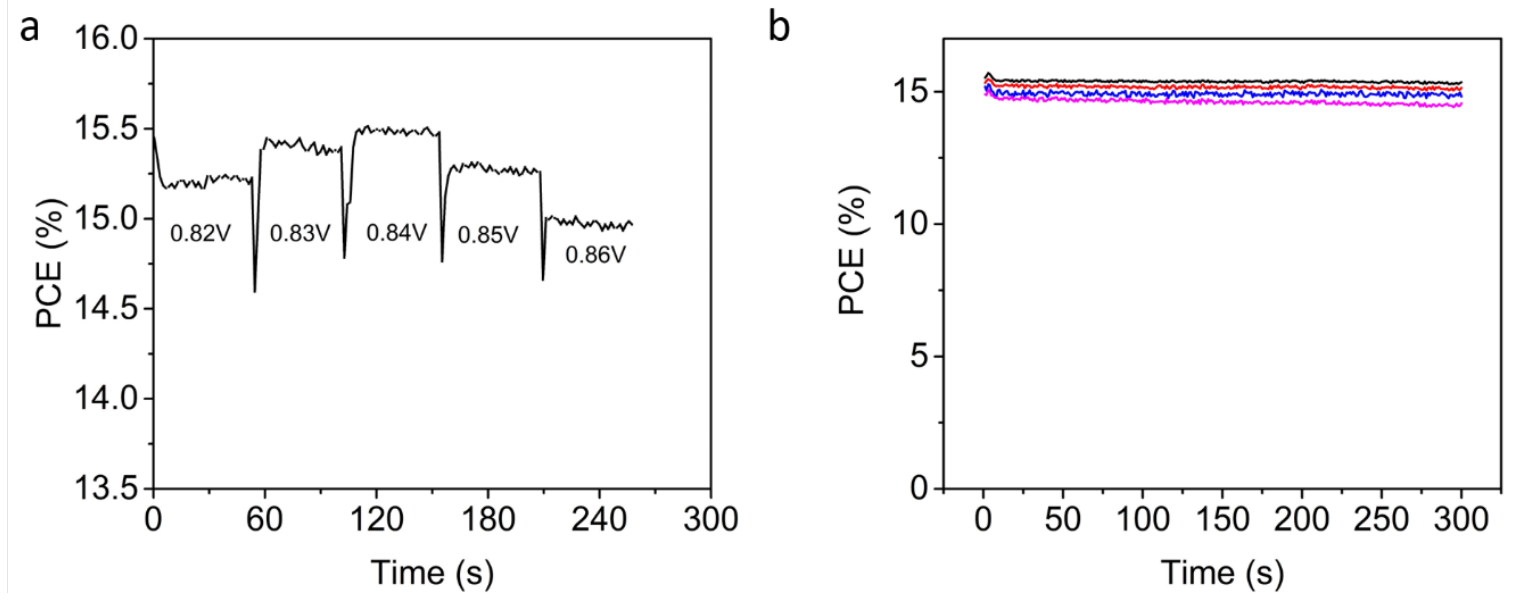

Figure S7. Stabilized efficiency of the champion laminated device at different biases near the maximum power point (a) and four devices measured at $0.84 \mathrm{~V}$ (maximum power point) bias for 5 min (b).

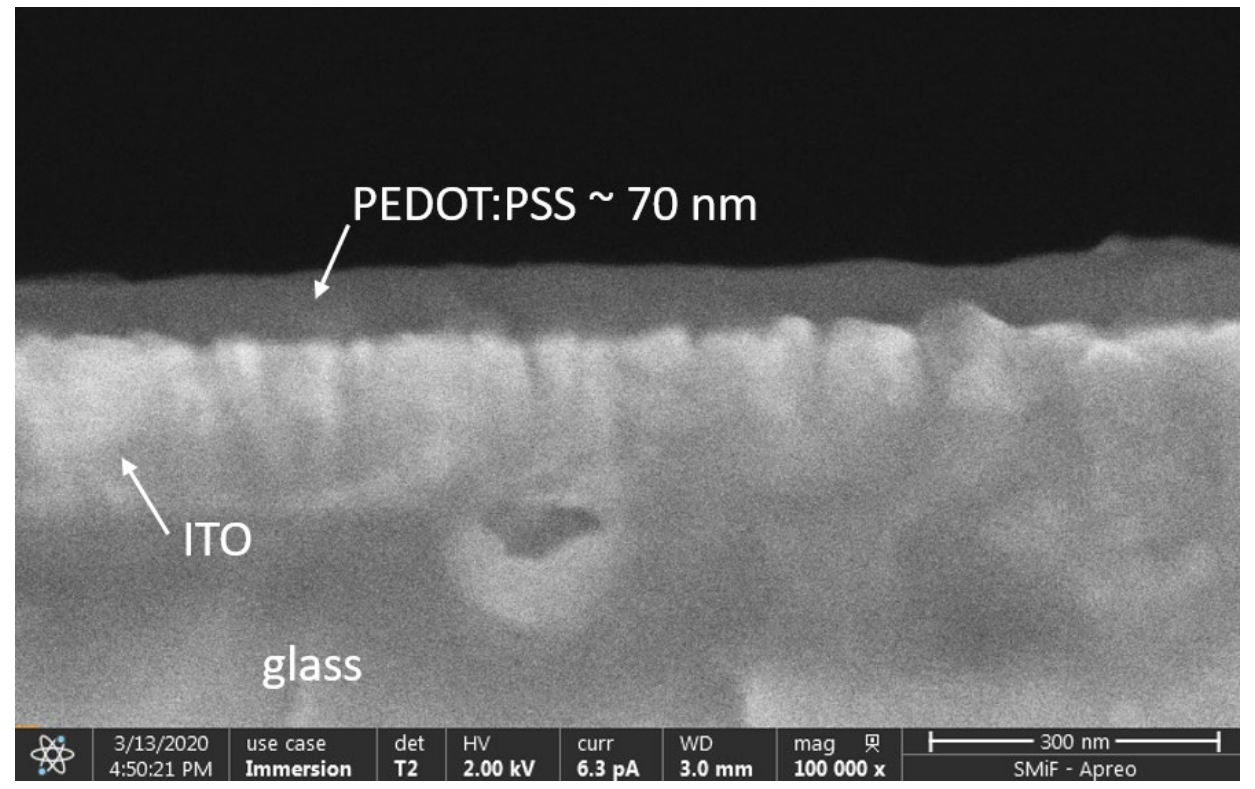

Figure S8. Cross-section SEM of PEDOT:PSS layer on ITO glass. 


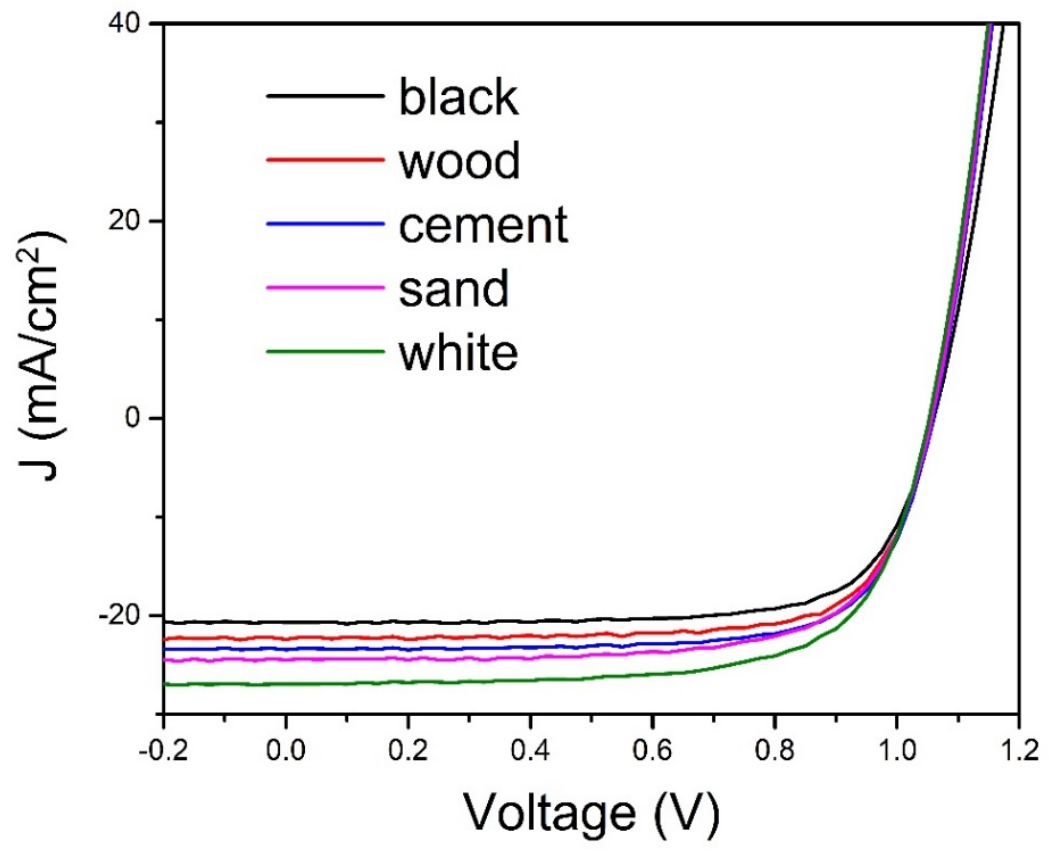

Figure S9. J-V reverse scans of the bifacial device under 1-sun illumination with different background.

The background is tilted $45^{\circ}$ with respect to the device.

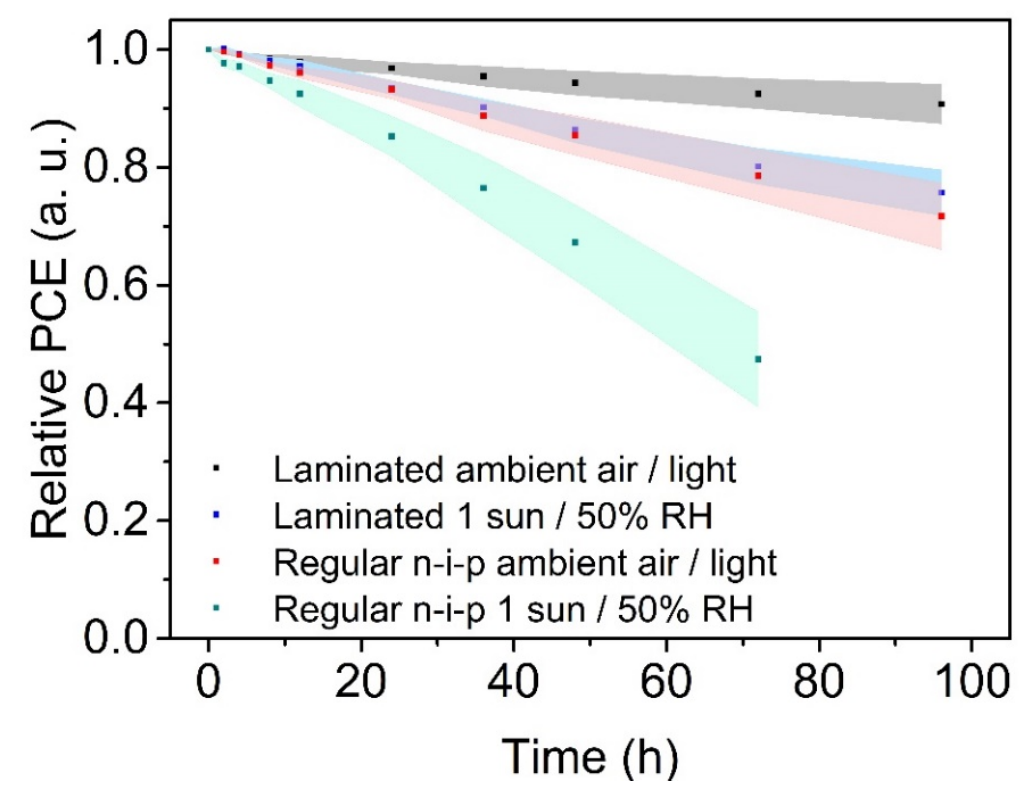

Figure S10. Comparison of relative performances over 100 hours of the laminated devices and the conventional $\mathrm{SnO}_{2}$ based devices in ambient light/air and 1 sun/50\% relative humidity conditions. 


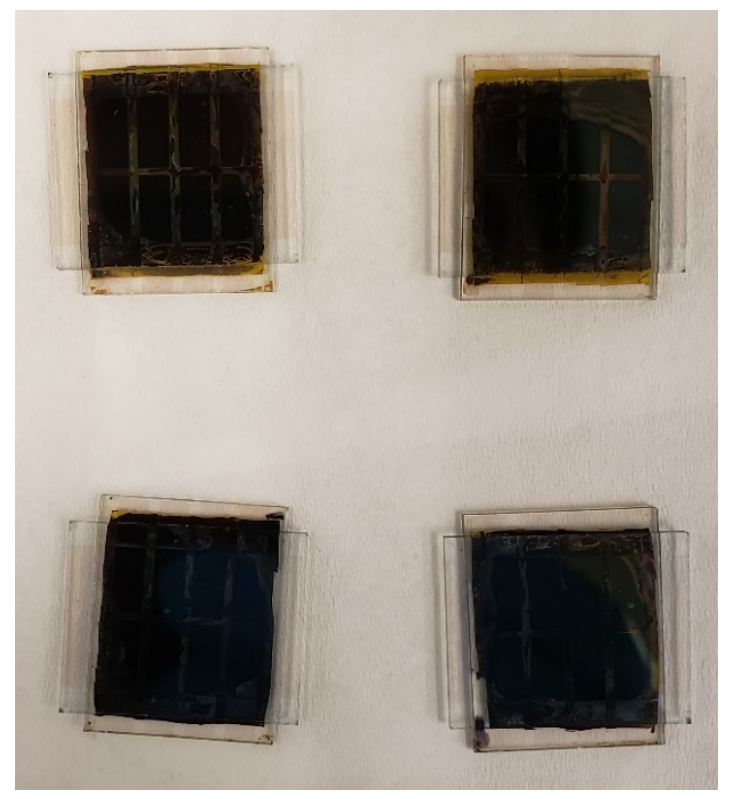

Figure S11. Images of the laminated devices with the same device structure and within the same device fabrication run after 100 hours at room temperature under open circuit condition in ambient light/air (bottom two) and 1 sun/50\% relative humidity conditions (top two). 


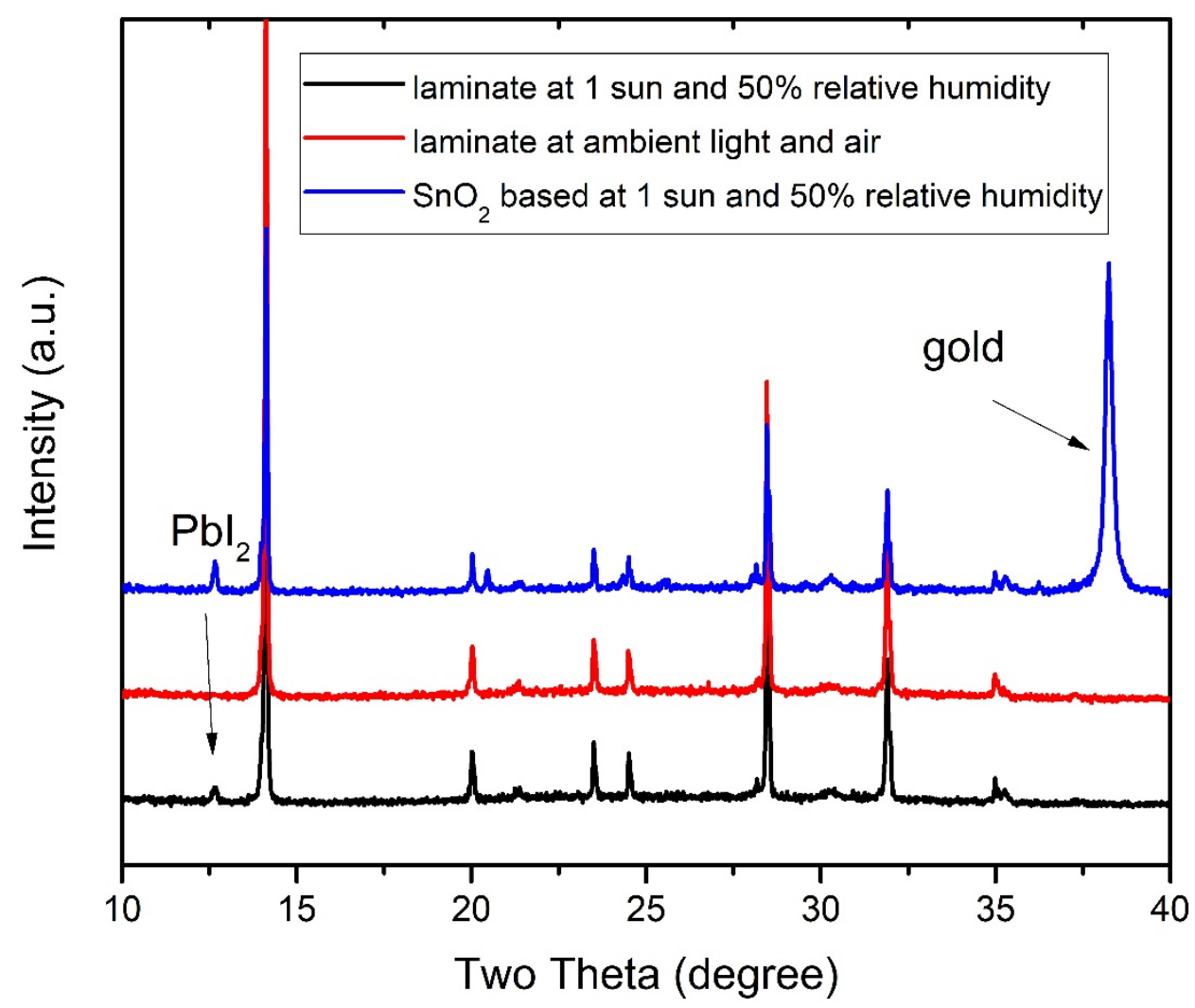

Figure $\mathrm{S} 12$. XRD analysis of peeled-apart laminated devices and $\mathrm{SnO}_{2}$-based $\mathrm{n}$-i-p type device after aging for 100 hours at room temperature under open circuit condition in ambient light/air and 1 sun/50\% relative humidity conditions.

Table S1. Comparison of the champion bifacial laminated device and the conventional $\mathrm{SnO}_{2}$-based $\mathrm{n}$-i-p type device under reverse scan

\begin{tabular}{|c|c|c|c|c|}
\hline Device type & $\mathrm{V}_{\mathrm{oc}}(\mathrm{V})$ & $\mathrm{J}_{\mathrm{sc}}\left(\mathrm{mA} / \mathrm{cm}^{2}\right)$ & Fill Factor (\%) & PCE (\%) \\
\hline Bifacial device & 1.044 & 20.6 & 72.8 & 15.77 \\
\hline $\mathrm{SnO}_{2}$ device & 1.068 & 21.2 & 77.1 & 17.46 \\
\hline
\end{tabular}


a

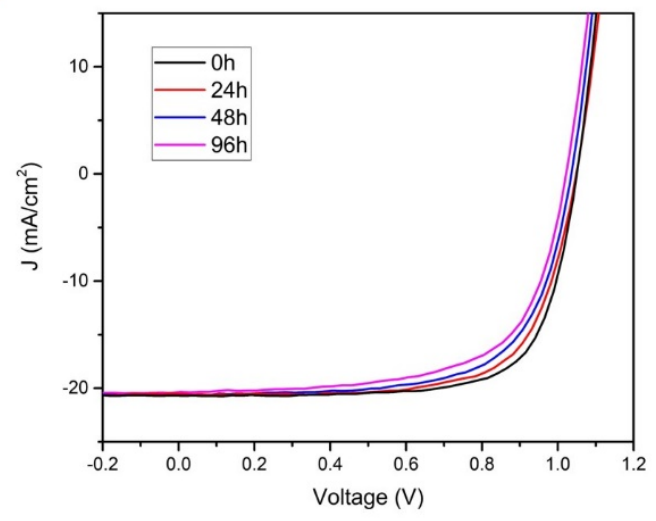

b

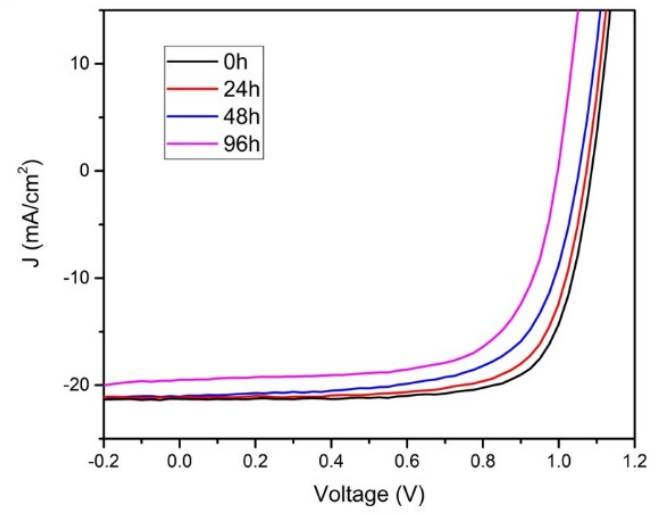

Figure S13. J-V scans of (a) laminated bifacial device (front side) and (b) conventional $\mathrm{SnO}_{2}$-based n-i-p device after aging for various amounts of time at room temperature under open circuit condition in ambient light/air, relative humidity $\sim 30-40 \%$.

\section{Reference}

1. Dunlap-Shohl, W. A.; Li, T.; Mitzi, D. B. Interfacial Effects during Rapid Lamination within $\mathrm{MAPbl}_{3}$ Thin Films and Solar Cells. ACS Appl. Energy Mater. 2019, 2, 5083-5093. 